\title{
Pancreatic Ductal Adenocarcinoma: Long-Term Survival Does Not Equal Cure
}

\section{Citation}

Ferrone, Cristina R., Rafael Pieretti-Vanmarcke, Jordan P. Bloom, Hui Zheng, Jackye Szymonifka, Jennifer A. Wargo, Sarah P. Thayer, et al. 2012. Pancreatic ductal adenocarcinoma: Long-term survival does not equal cure. Surgery 152(3): S43-S49.

\section{Published Version}

doi:10.1016/j.surg.2012.05.020

\section{Permanent link}

http://nrs.harvard.edu/urn-3:HUL.InstRepos:12601542

\section{Terms of Use}

This article was downloaded from Harvard University's DASH repository, and is made available under the terms and conditions applicable to Other Posted Material, as set forth at http:// nrs.harvard.edu/urn-3:HUL.InstRepos:dash.current.terms-of-use\#LAA

\section{Share Your Story}

The Harvard community has made this article openly available.

Please share how this access benefits you. Submit a story.

Accessibility 


\title{
Pancreatic ductal adenocarcinoma: Long-term survival does not equal cure
}

\author{
Cristina R. Ferrone, MDa ${ }^{a}$, Rafael Pieretti-Vanmarcke, MDa, Jordan P. Bloom, MD ${ }^{a}$, Hui \\ Zheng, PhD ${ }^{b}$, Jackye Szymonifka, PhD $^{b}$, Jennifer A. Wargo, MD $^{a}$, Sarah P. Thayer, MD, \\ PhD $^{\mathrm{a}}$, Gregory Y. Lauwers, MD $^{\mathrm{c}}$, Vikram Deshpande, MD $^{\mathrm{C}}$, Mari Mino-Kenudson, MD $^{\mathrm{C}}$, \\ Carlos Fernández-del Castillo, MD ${ }^{a}$, Keith D. Lillemoe, MD ${ }^{a}$, and Andrew L. Warshaw, MDa \\ aDepartment of Surgery, Massachusetts General Hospital, Harvard Medical School, Boston, MA \\ bDepartment of Statistics, Massachusetts General Hospital, Harvard Medical School, Boston, MA \\ 'Department of Pathology, Massachusetts General Hospital, Harvard Medical School, Boston, \\ MA
}

\begin{abstract}
Background-Pancreatic ductal adenocarcinoma represents $90 \%$ of pancreatic cancers and is an important cause of cancer death in the United States. Operative resection remains as the only treatment providing prolonged survival, but even after a curative resection, 5-year survival rates are low. Our aim was to identify the prognostic factors for long-term survival after resection of pancreatic ductal adenocarcinoma related to patients, treatments, and tumor biology.
\end{abstract}

Methods-Retrospective review identified 959 patients who underwent resection of their pancreatic adenocarcinoma between February 1985 and December 2010, of whom 499 were resected before November 2006 and represent the cohort we describe in this study. Patient, tumor, and treatment-related variables were assessed for their associations with 5- and 10-year overall survival.

Results-Of the 499 patients, $49 \%$ were female and median age was 65 years. The majority of patients had stage IIb disease (60\%). Actual 5-year survival after resection of pancreatic adenocarcinoma was 19\% (95/499), and actual 10-year survival was 10\% (33/329). Significant clinicopathologic factors predicting 5- and 10-year survival were negative margins and negative nodal status. Interestingly, $41 \%$ (39/95) of long-term survivors had positive nodes and $24 \%$ (23/95) had positive margins.

Conclusion-Pancreatic ductal adenocarcinoma demonstrates a very heterogeneous biology, but patients with negative resection margins and node negative cancers are more likely to survive 5 years after resection. However, our series demonstrates that the biology of the cancer rather than simple pathologic factors determine a patient's prognosis.

Recently, the American Cancer Society reported that during the last decade overall rates of cancer and cancer death have dropped. ${ }^{1}$ This is believed to be largely because of a decrease in cigarette smoking and an increase in cancer screening. Conversely, pancreatic cancer rates are on the rise. ${ }^{2}$ This fact, in combination with the dismal prognosis and lack of early detection, make pancreatic cancer a growing concern. Additionally, societal awareness of

(c) 2012 Mosby, Inc. All rights reserved.

Reprint requests: Cristina R. Ferrone, MD, Massachusetts General Hospital, 15 Parkman St WAC 460, Boston, MA 02114. cferrone@partners.org. 
pancreas cancer has been heightened owing to numerous celebrities who have recently died of the disease.

The American Cancer Society estimates that there will be 44,030 new cases of pancreatic cancer diagnosed in 2011. This is an increase of almost $19 \%$ from 2007. ${ }^{2}$ The American Cancer Society also estimates that there will be 37,660 deaths from pancreatic cancer in 2011, making it the fourth leading cause of cancer-related death among men and the third leading cause of cancer-related death among women in the United States. ${ }^{3}$ An estimated $\$ 1.9$ billion is spent on the disease each year. ${ }^{3}$ Despite progress in our understanding of pancreatic cancer, the 5-year survival for all-comers remains 5\% and has not changed over the past 3 decades. ${ }^{4}$ Even after operative resection, actual 5 -year survival is only $12 \%$ in other series. ${ }^{5}$

The aims of this study were to evaluate the actual 5- and 10-year overall survivals of patients who have undergone operative resection of pancreatic ductal adenocarcinoma. The second aim was to evaluate clinicopathologic factors predicting long-term survival.

\section{METHODS}

We retrospectively reviewed a database of all patients who underwent pancreatic resection at the Massachusetts General Hospital between February 1985 and November 2006 and identified 499 patients who underwent resection for pathologically confirmed pancreatic ductal adenocarcinoma.

Patient-, tumor-, and treatment-related variables were evaluated. Patient factors evaluated included age, gender, smoking status, and family history. Treatment factors included the type of operation, adjuvant therapy, and status at last follow-up. Pathologic factors included tumor size, nodes, metastases, TNM stage, margin (positive or negative), and vascular, lymphatic, and perineural invasion and differentiation (well, moderate, or poor). Maximal tumor size was determined and defined as the maximum diameter at pathological analysis. Follow-up was obtained through office records and the social security death index.

Patients were divided into short-term survivors ( $3-\underline{20}$ months), intermediate term survivors ( $>20-<60$ months), and long-term survivors ( $>60$ months). There were 17 perioperative mortalities within 90 days of operative resection that were not included in Table I. Utilizing SAS Version 9.2 (SAS, Inc, Chicago, IL), both univariate and multivariate modeling were performed. Continuous variables were expressed as median or mean values \pm standard deviation and were compared using an independent samples $t$-test. Chi-square $P$-values were calculated for the comparison of clinical characteristics between survivorship groupings (Table I). Cox regression modeling was used to determine the effect of prognostic factors on overall survival. We calculated odds ratios using logistic regression modeling to determine factors associated with short- and long-term (Tables II and III) survivorship. Both univariate and multivariate models were created. Kaplan-Meier methodology was used for the overall survival curve and it was computed from the time of operative resection to the date of last follow-up. The institutional internal review board approved this study, and none of the authors have any conflict of interest.

\section{RESULTS}

\section{Clinicopathologic factors}

Between February 1985 and November 2006, 499 patients underwent complete gross resection of a pathologically confirmed pancreatic ductal adenocarcinoma. The cohort was approximately half female (49\%) with a median age at diagnosis of 65 years (range, 31-91). 
The majority of patients (84\%) underwent pancreaticoduodenectomy and had stage IIb disease (60\%). One third of the patients 35\% (174/499) received chemotherapy and 66\% (329/499) received radiotherapy with chemotherapy. Even though receiving chemotherapy is a time-dependent covariate, not receiving chemotherapy was independently associated with decreased survival after the pancreatic operation $(P=.04)$. The clinicopathologic characteristics of the overall cohort are listed in Table I.

\section{Overall survival}

Patients were divided into short-term survivors ( $3-\underline{20}$ months), intermediate term survivors ( $>20-<60$ months), and long-term survivors ( $>60$ months). The final cohort contained 499 patients, including 243 short-term survivors, 144 intermediate term survivors, and 95 longterm survivors. The median follow-up for the entire cohort was 19 months (range, 1-271). The overall postoperative mortality at 90 days was $3.4 \%$ (17/499). The postoperative mortality after pan-creaticoduodenectomy was $16 / 418$ (3.8\%) and after distal pancreatectomy $1 / 66(1.5 \%)$. The 14 perioperative mortalities were included in the shortterm survivor group. Overall survival for the entire cohort is demonstrated in the Figure. The actual 5-year survival was 19\% (95/499). Almost 1/3 of patients survived between 20 and 60 months and $49 \%$ survived less than 20 months. Within the group of 95 patients who survived 5 years, $41 \%$ had stage IIB, $31 \%$ stage IIA, $15 \%$ stage IB, and $14 \%$ stage IA cancers. Unfortunately, 5-year survival does not represent cure, with 13\% (12/95) of the patients dying of disease after this time. Currently, 62 patients have survived between 5 and 10 years of whom 56 are still alive. The longest survivor is alive 22.5 years after her operation. Actual 10-year survival was 10\% (33/329).

\section{Prognostic factors}

Short-term, intermediate, and long-term survivors had significant differences in their R0/R1 status, histologic tumor grade, lymph node status, and TNM staging on univariate analysis (Table I). Patients with negative margins, well-differentiated tumors, negative nodes and a lower TNM stage were more likely to experience long-term survival. When comparing patients who survived 5-10 years with those who survived $\geq 10$ years, the only significant difference was the percentage of R0 resections $(P=.01)$. Otherwise, the differences in clinical characteristics between the 2 survivorship groups were not statistically significant (Table IV).

Univariate logistic regression models built to predict overall survival from the date of resection demonstrated that positive margins, higher stage, positive nodes, and increased tumor size were independently associated with decreased overall survival (Table II). Multivariate analysis demonstrates that negative margins and negative nodes were independently associated with longer survival (Table III).

\section{DISCUSSION}

Most pancreatic cancers are diagnosed at an advance stage. This, together with the aggressiveness of the disease and the lack of effective systemic therapies, results in low rates of overall survival. Operative resection remains the only chance for long-term survival, despite advances in adjuvant and neoadjuvant therapies. The perioperative morbidity and mortality of pancreatic surgery has decreased to $24 \%$ and $2 \%$, respectively, over the last 30 years. ${ }^{6-8}$ Despite all of these improvements, the overall survival of patients with pancreatic adenocarcinoma remains low. In our cohort of 499 patients resected between 1985 and 2006, the actual 5- and 10-year overall survivals were $19 \%$ and $10 \%$, respectively. The actual 5year overall survival of $19 \%$ is $2 \%$ higher than what we reported in $1992 .{ }^{9}$ Although these results are better, survival remains low. Series from John Hopkins University and Memorial 
Sloan Kettering Cancer Center report a similar 5-year overall survival of $18 \%$ and $12 \%$, respectively (Table V).

Analysis of clinicopathologic variables in our 5-year survivors demonstrates the challenges in prognosis for an individual patient with this disease. Increased tumor size, R1 status, positive nodes, advanced stage disease, and not receiving chemotherapy were independently associated with decreased survival after resection on univariate analysis. Only N stage and margin status were significant predictors of long-term survival in our cohort. Similarly, other large series identified margin status as a predictor of long-term survival. $5,7,10$ Unfortunately, margin status is often affected by the location and size of the tumor. However, positive margins do not preclude long-term survival, because $25 \%$ of the 5-year survivors in our series had an operation with positive margins. Negative nodes also emerged as a prognostic factor for long-term survival in our series. Multiple studies identify stage as a prognostic marker. We did not identify stage, but clearly nodal status and American Joint Committee on Cancer stage are closely linked. In our cohort $41 \%$ (39/95) of 5-year survivors and $44 \%$ (14/33) of 10-year survivors had positive lymph nodes at the time of operative resection. These node-positive, long-term survivors exemplify the heterogeneous tumor biology of pancreatic cancer.

The use of adjuvant chemotherapy has increased during the last 2 decades in the United States. ${ }^{11}$ Although the aim of our study was not to measure the benefit conferred by adjuvant therapy, we did notice that between the first 10 years of our study (1985-1995) only $1.4 \%$ of the patients received chemotherapy, compared to $47.7 \%$ between 1995 and 2006. Some of the long-term survivors may have benefited from adjuvant therapy because chemotherapy improved survival in our series and has been demonstrated to improve disease-free survival after operative resection by about $10 \%$ in a randomized, controlled trial. ${ }^{12}$ Despite a shift in adjuvant chemotherapy from 5-fluorouracil to gemcitabine over the last 2 decades, these 2 agents have demonstrated equivalent efficacy on disease-free and overall survivals. ${ }^{13,14}$ Therefore, the increased use of chemotherapy over time in our series most likely improved the time to recurrence rather than the specific agent used.

Overall survival did not change significantly during the 2-decade study period; however, perioperative 90 -day mortality decreased by half from $5 \%$ to $2.5 \%$ between the first and second decade. Perioperative mortality has been reported at most centers around $u \% .{ }^{8,15} \mathrm{We}$ report in this study a $3.2 \%$ perioperative 90 -day mortality rate for the entire cohort. This decrease in mortality is multi-factorial, to which the development of tertiary care centers with multidisciplinary teams and the specialization of surgeons in pancreas surgery has contributed. ${ }^{16,17}$

Long-term survivors present a unique cohort of patients to study. Despite positive margins and/or positive nodes some patients are still alive. Whereas $66 \%$ of the short-term survivors and $63 \%$ of the intermediate survivors had stage IIB disease, $41 \%$ of the 5 -year survivors had positive nodes. Conversely, 28\% (17/61) of patients with stage I disease died of the disease within 20 months, and only 44\% (27/61) lived beyond 5 years. Therefore, stage alone is unable to reliably predict prognosis. Positive margins were demonstrated in $47 \%$ of short-term survivors and $31 \%$ of intermediate survivors, yet $24 \%$ of 5 -year survivors also underwent an R1 resection. Although these differences are significant they highlight that the pace of progression is heterogeneous and determined by biology rather than pathology. These tumors may have a lower number of cancer-initiating cells (aldehyde dehydrogenasehigh), cells that possess properties of self-renewal, tumor initiation, and differentiation. ${ }^{18}$ Other series have demonstrated a worse prognosis in patients who have more mesenchymal tumors, which express vimentin, fibronectin, and N-cadherin, ${ }^{18-20}$ so perhaps these longterm survivors may have tumors with more epithelial features. Although many gene 
amplifications and deletions, epigenetic changes, and proteomic abnormalities have been identified, the biology of pancreatic cancer is currently still poorly understood.

Interestingly, 5-year survival is not consistent with cure as an additional 23 patients died 5 years after their operation. Of these patients 12 died of disease, 10 patients died of unknown causes, and 1 patient died of a non-cancer-related cause. Therefore, of our 5-year survivors, $58 \%$ (55/95) are still alive. Several patients in our cohort have relapsed $>10$ years after the resection of their primary pancreatic adenocarcinoma. Two patients developed isolated lung metastases and underwent pulmonary resections to help control their disease. This late relapse perhaps suggests that the interaction of the immune system with the tumor varies over time and during the progression of the malignancy. The cells we later identify as recurrences may have been controlled by the immune system from the time of the resection of the primary cancer. This phenomenon of tumor escape can occur through a variety of mechanisms, including inhibition or suppression of T-cell recognition, an increase in regulatory $\mathrm{T}$ cells, alterations in the immunologic checkpoints resulting in downregulation of T cells, and many others. ${ }^{21-23}$ By studying this cohort of patients, we hope to elucidate some of the contributing factors to recurrence.

In conclusion, this series confirms that ductal adenocarcinoma of the pancreas has an implacable prognosis, even after resection, with actual 5- and 10-year survivals of 19\% and $10 \%$, respectively. However, our series exemplifies that a patient's prognosis is determined by tumor biology rather than clinicopathologic factors, because there is a striking discordance between pathology, stage, and survival. Additional efforts are needed to decrease morbidity associated with pancreatic resection and improve screening for early detection; however, mostly we need to intensify the search for new and effective therapies by understanding the diverse biology of the long-term survivors.

\section{REFERENCES}

1. Perrone F, Marangolo M, Di Costanzo F, et al. Cost of insurance policies for investigator-initiated cancer clinical trials in Italy. Tumori. 2005; 91:373-379. [PubMed: 16277110]

2. Society, AC. American Cancer Society Facts and Figures 2007. Atlanta: American Cancer Society; 2007. Pancreatic adenocarcinoma.

3. Howlader, N.; Noone, AM.; Krapcho, M., et al., editors. Bethesda: National Cancer Institute; SEER cancer statistics review, 1975-2009. (vintage 2009 populations) [updated 2012 Apr]. Available from: http://seer.cancer.gov/csr/1975_2009_pops09/

4. Jemal A, Siegel R, Xu J, et al. Cancer statistics, 2010. CA Cancer J Clin. 2010; 60:277-300. [PubMed: 20610543]

5. Ferrone CR, Brennan MF, Gonen M, et al. Pancreatic adenocarcinoma: the actual 5-year survivors. J Gastrointest Surg. 2008; 12:701-706. [PubMed: 18027062]

6. Crist DW, Sitzmann JV, Cameron JL. Improved hospital morbidity, mortality, and survival after the Whipple procedure. Ann Surg. 1987; 206:358-365. [PubMed: 3632096]

7. Han SS, Jang JY, Kim SW, et al. Analysis of long-term survivors after surgical resection for pancreatic cancer. PAN-CREAS. 2006; 32:71-75.

8. Sohn TA, Yeo CJ, Cameron JL, et al. Resected adenocarcinoma of the pancreas-616 patients: results, outcomes, and prognostic indicators. J Gastrointest Surg. 2000; 4:567-579. [PubMed: 11307091]

9. Warshaw AL, Fernandez-del Castillo C. Pancreatic carcinoma. N Engl J Med. 1992; 326:455-465. [PubMed: 1732772]

10. Winter JM, Cameron JL, Campbell KA, et al. 1423 pancreati-coduodenectomies for pancreatic cancer: a single-institution experience. J Gastrointest Surg. 2006; 10:1199-1210. [PubMed: 17114007] 
11. Mayo SC, Gilson MM, Herman JM, et al. Management of patients with pancreatic adenocarcinoma: national trends in patient selection, operative management, and use of adjuvant therapy. J Am Coll Surg. 2012; 214:33-45. [PubMed: 22055585]

12. Oettle H, Post S, Neuhaus $\mathrm{P}$, et al. Adjuvant chemotherapy with gemcitabine vs observation in patients undergoing curative-intent resection of pancreatic cancer: a randomized controlled trial. JAMA. 2007; 297:267-277. [PubMed: 17227978]

13. Neoptolemos JP, Stocken DD, Bassi C, et al. Adjuvant chemotherapy with fluorouracil plus folinic acid vs gemcitabine following pancreatic cancer resection: a randomized controlled trial. JAMA. 2010; 304:1073-1081. [PubMed: 20823433]

14. Regine WF, Winter KA, Abrams R, et al. Fluorouracil-based chemoradiation with either gemcitabine or fluorouracil chemotherapy after resection of pancreatic adenocarcinoma: 5-year analysis of the U.S. Intergroup/RTOG 9704 phase III trial. Ann Surg Oncol. 2011; 18:1319-1326. [PubMed: 21499862]

15. Fischer M, Matsuo K, Gonen M, et al. Relationship between intraoperative fluid administration and perioperative outcome after pancreaticoduodenectomy: results of a prospective randomized trial of acute normovolemic hemodilution compared with standard intraoperative management. Ann Surg. 2010; 252:952-958. [PubMed: 21107104]

16. Lieberman MD, Kilburn H, Lindsey M, et al. Relation of perioperative deaths to hospital volume among patients undergoing pancreatic resection for malignancy. Ann Surg. 1995; 222:638-645. [PubMed: 7487211]

17. Pawlik TM, Laheru D, Hruban RH, et al. Evaluating the impact of a single-day multidisciplinary clinic on the management of pancreatic cancer. Ann Surg Oncol. 2008; 15:2081-2088. [PubMed: 18461404]

18. Rasheed ZA, Yang J, Wang Q, et al. Prognostic significance of tumorigenic cells with mesenchymal features in pancreatic adenocarcinoma. J Natl Cancer Inst. 2010; 102:340-351. [PubMed: 20164446]

19. Javle MM, Gibbs JF, Iwata KK, et al. Epithelial-mesenchymal transition (EMT) and activated extracellular signal-regulated kinase (p-Erk) in surgically resected pancreatic cancer. Ann Surg Oncol. 2007; 14:3527-3533. [PubMed: 17879119]

20. Krantz SB, Shields MA, Dangi-Garimella S, et al. Contribution of epithelial-to-mesenchymal transition and cancer stem cells to pancreatic cancer progression. J Surg Res. 2012; 173:105-112. [PubMed: 22099597]

21. Lehner PJ, Surman MJ, Cresswell P. Soluble tapasin restores MHC class I expression and function in the tapasin-negative cell line .220. Immunity. 1998; 8:221-231. [PubMed: 9492003]

22. Pardoll D. Does the immune system see tumors as foreign or self? Annu Rev Immunol. 2003; 21:807-839. [PubMed: 12615893]

23. Mapara MY, Sykes M. Tolerance and cancer: mechanisms of tumor evasion and strategies for breaking tolerance. J Clin Oncol. 2004; 22:1136-1151. [PubMed: 15020616]

24. Ahmad NA, Lewis JD, Ginsberg GG, et al. Long term survival after pancreatic resection for pancreatic adenocarcinoma. Am J Gastroenterol. 2001; 96:2609-2615. [PubMed: 11569683]

25. Cleary SP, Gryfe R, Guindi M, et al. Prognostic factors in resected pancreatic adenocarcinoma: analysis of actual 5-year survivors. J Am Coll Surg. 2004; 198:722-731. [PubMed: 15110805] 
Overall survival from date of first surgery

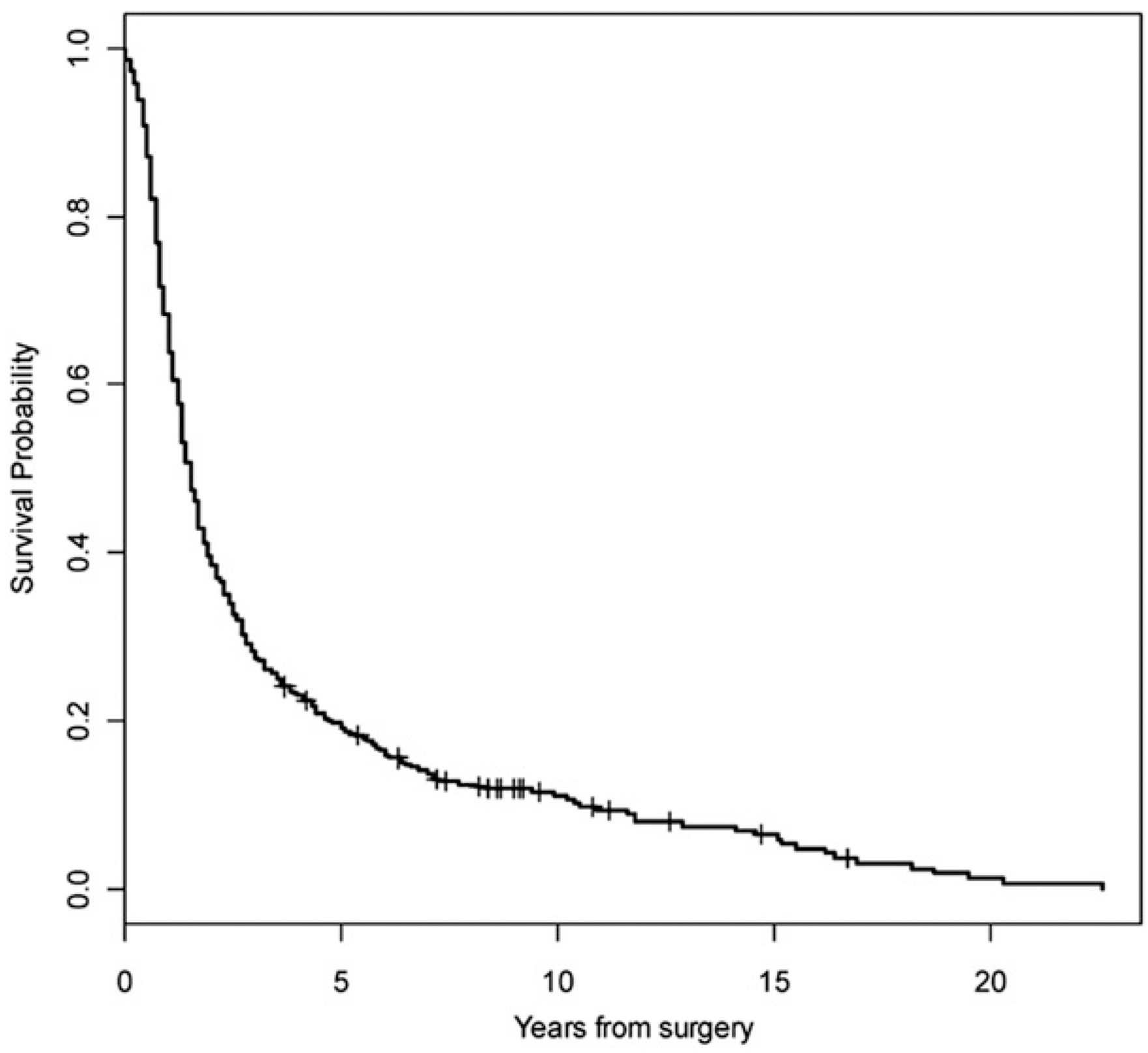

Figure.

Overall survival for all patients (Kaplan-Meier). 
Ferrone et al.

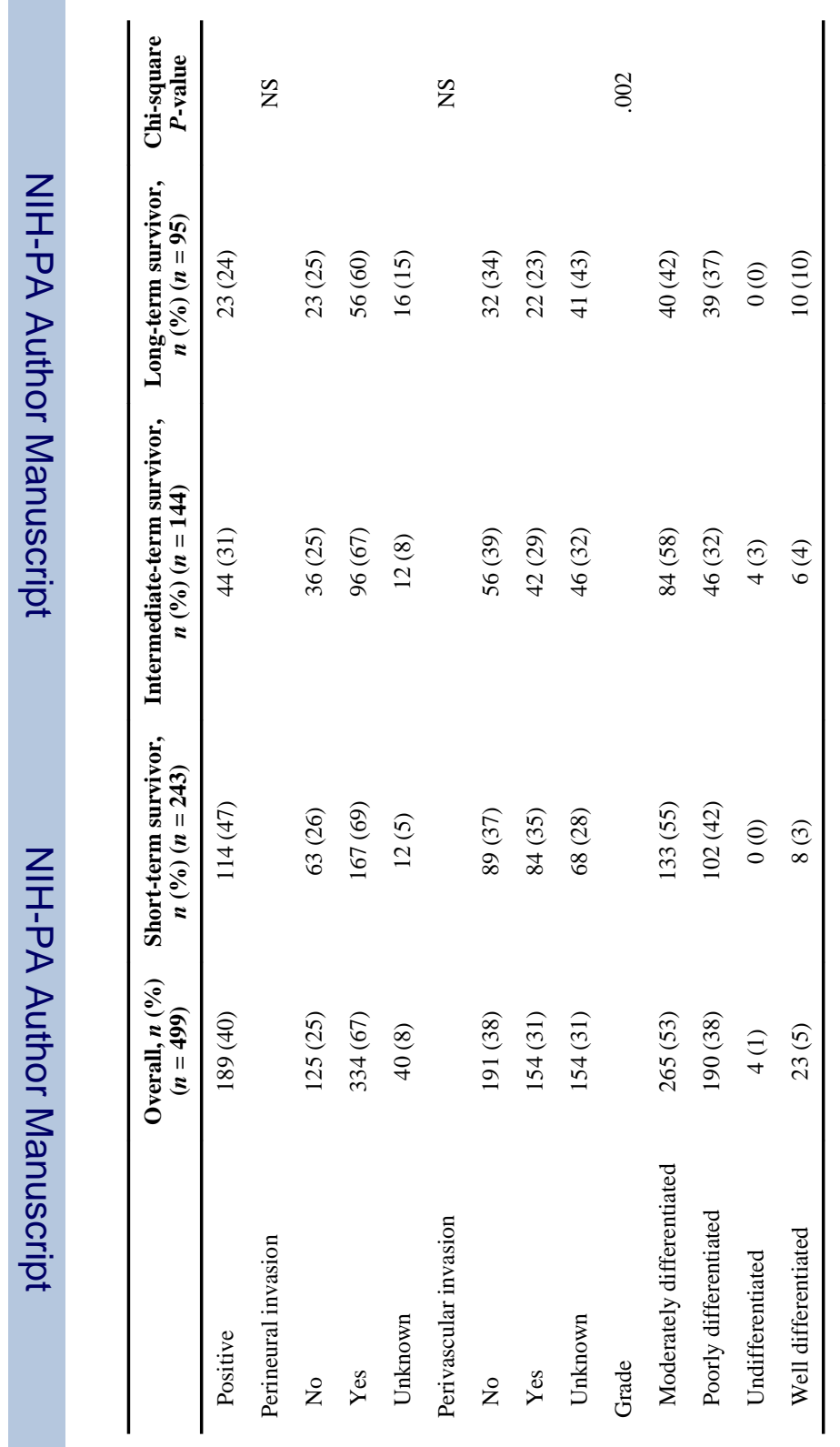

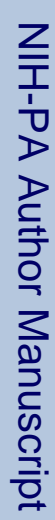


Table II

Univariate logistic regression model predicting long-term survival

\begin{tabular}{lcc}
\hline Long-term univariate & Odds ratio $(\mathbf{9 5 \%}$ confidence interval) & $\boldsymbol{P}$-value \\
\hline Head & $0.712(0.40-1.28)$ & .258 \\
Male & $1.232(0.78-1.94)$ & .368 \\
Pancreaticoduodenectomy & $0.911(0.50-1.67)$ & .763 \\
R0R1:R1 & $0.447(0.27-0.75)$ & .002 \\
Age/10 & $1.009(0.81-1.26)$ & .936 \\
Received chemo & $1.499(0.94-2.39)$ & .089 \\
H vs D:H & $0.851(0.46-1.59)$ & .612 \\
pN & $0.318(0.20-0.51)$ & $<.001$ \\
Poorly differentiated & $1.142(0.72-1.81)$ & .572 \\
Tumor size & $0.774(0.64-0.94)$ & .010 \\
Stage 3-4 & NA & - \\
T stage 3-4 & $0.434(0.26-0.72)$ & .001 \\
\hline
\end{tabular}

Because there were no stage 3-4 patients in the long-term survivor group, this effect was not analyzable (NA). 
Table III

Multivariate logistic regression model predicting long-term survival

\begin{tabular}{lcc}
\hline Multivariate & $\begin{array}{c}\text { Odds ratio (95\% } \\
\text { confidence interval) }\end{array}$ & $\boldsymbol{P}$-value \\
\hline R0/R1:R1 & $0.472(0.27-0.82)$ & .008 \\
$\mathrm{pN}$ & $0.300(0.18-0.50)$ & $<.001$ \\
\hline
\end{tabular}


Table IV

Patients characteristics of long-term survivors by length of survival time

\begin{tabular}{|c|c|c|c|c|}
\hline Variable & $\begin{array}{l}\text { Long-term survivors } \\
\text { (overall), } n(\%)(n=95)\end{array}$ & $\begin{array}{c}\qquad \text { - and }<10 \text {-year } \\
\text { survivorship, } n(\%)(n=62)\end{array}$ & $\begin{array}{l}\geq 10 \text {-yr survivorship, } \\
\quad n(\%)(n=33)\end{array}$ & $\begin{array}{c}\text { Chi-square } \\
P \text {-value }\end{array}$ \\
\hline Gender & & & & NS \\
\hline Female & $42(45)$ & $30(48)$ & $12(37)$ & \\
\hline Male & $53(55)$ & $32(52)$ & $21(63)$ & \\
\hline Tumor location & & & & NS \\
\hline Head & $77(81)$ & $51(82)$ & $26(79)$ & \\
\hline Body & $7(7)$ & $5(8)$ & $2(6)$ & \\
\hline Tail & $8(9)$ & $4(7)$ & $4(12)$ & \\
\hline Operation & & & & NS \\
\hline Pancreaticoduodenectomy & $79(83)$ & $53(86)$ & $26(79)$ & \\
\hline Distal pancreatectomy & $11(12)$ & $7(11)$ & $4(12)$ & \\
\hline Total pancreatectomy & $5(5)$ & $2(3)$ & $3(9)$ & \\
\hline Stage of resected patients & & & & NS \\
\hline IA & $13(14)$ & $9(15)$ & $4(12)$ & \\
\hline IB & $14(15)$ & $7(11)$ & $7(21)$ & \\
\hline IIA & $29(31)$ & $22(35)$ & $7(21)$ & \\
\hline IIB & $39(41)$ & $24(39)$ & $15(46)$ & \\
\hline pT & & & & NS \\
\hline 1 & $13(14)$ & $9(15)$ & $5(13)$ & \\
\hline 2 & $18(19)$ & $8(13)$ & $10(31)$ & \\
\hline 3 & $64(67)$ & $45(72)$ & $18(56)$ & \\
\hline $\mathrm{pN}$ & & & & NS \\
\hline 0 & $56(59)$ & $38(61)$ & $19(56)$ & \\
\hline 1 & $39(41)$ & $24(39)$ & $14(44)$ & \\
\hline Margin (R0R1) & & & & .014 \\
\hline Negative & $72(76)$ & $42(68)$ & $30(91)$ & \\
\hline Positive & $23(24)$ & $20(32)$ & $3(9)$ & \\
\hline Perineural invasion & & & & NS \\
\hline No & $23(25)$ & $14(22)$ & $9(29)$ & \\
\hline Yes & $56(60)$ & $42(68)$ & $14(45)$ & \\
\hline Unknown & $16(15)$ & $6(10)$ & $9(26)$ & \\
\hline Perivascular invasion & & & & NS \\
\hline No & $32(34)$ & $18(29)$ & $13(42)$ & \\
\hline Yes & $22(23)$ & $17(28)$ & $4(13)$ & \\
\hline Unknown & $41(43)$ & $27(43)$ & $15(45)$ & \\
\hline Grade & & & & NS \\
\hline Moderately differentiated & $40(42)$ & $25(40)$ & $15(46)$ & \\
\hline Poorly differentiated & $39(37)$ & $25(40)$ & $14(42)$ & \\
\hline Well differentiated & $10(10)$ & $9(14)$ & $2(6)$ & \\
\hline
\end{tabular}




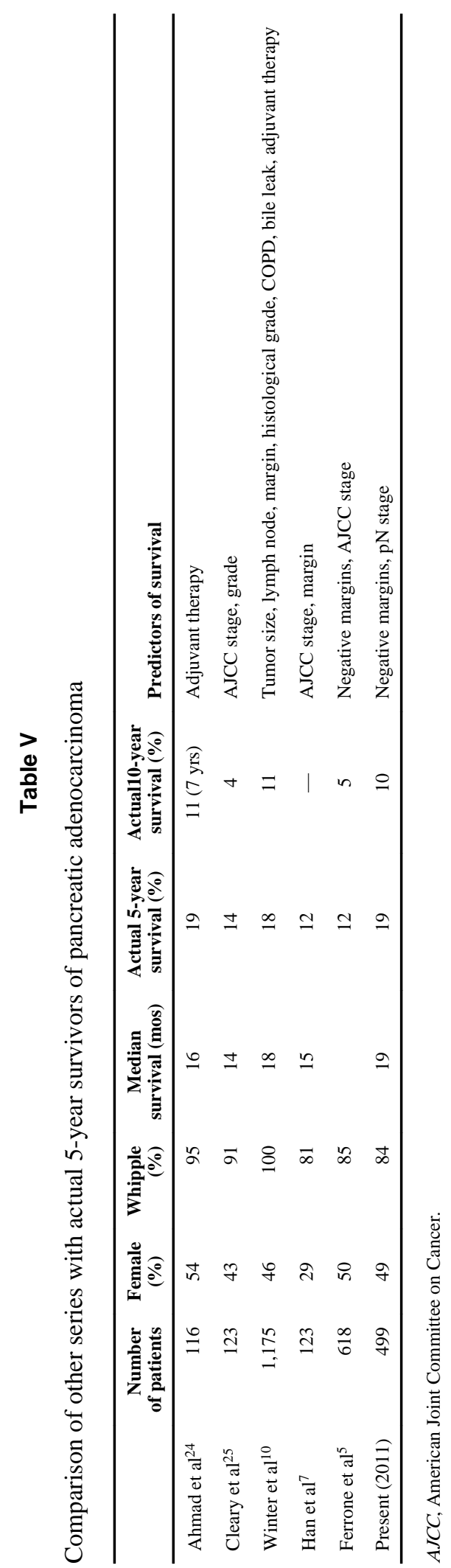

